\title{
Computational equation discovery of relationships between \\ sciendo container ship fuel consumption and hull and propeller \\ fouling phenomena
}

doi:10.2478/mape-2019-0002

Date of submission to the Editor: 04/2018

Date of acceptance by the Editor: 07/2018

MAPE 2019, volume 2, issue 1, pp. 24-30

Tomasz Cepowski*

ORCID ID: 0000-0001-8038-075X

Andrzej Drozd

Maritime University of Szczecin, Poland

\section{INTRODUCTION}

With an ever changing political and economic situation round the globe, together with a sharp rise in fuel prices, ever-increasing weather anomalies attributed to the warming of the climate caused by harmful emissions into the atmosphere have al resulted in measures to reduce fuel consumption in ships.

To counter these problems, the marine industry has introduced new methods to reduce fuel consumption and the amount of exhaust gases released to the atmosphere.

These methods can be divided into two categories:

- technical engine construction methods, power plant, use of new fuel types, etc.

- operational methods for determining optimum ship operational parameters for fuel consumption.

The operational methods for the reduction of fuel consumption, which have already been presented in many papers (Aligne, Papageorgiou \& Ramos, 1997; Christiansen, 1999; Yiyo, 2010), are usually based on theoretical calculations. These methods only are only able to focus on ship resistance calculated theoretically in calm water and rarely in any other weather conditions. Based on a theoretically calculated ship resistance in addition to overall ship efficiency, theoretical fuel consumption can then be calculated according to (Cepowski, 2015).

Accordingly, ship owners generally assume that current calculation methods are not sufficiently accurate to utilize the large amounts of data, that are currently available from systems installed on-board to monitor vessel fuel consumption. A typical example of such a simple method the use of the equation (Wiśniewski, Medyna \& Chomski, 2009, 2013):

$$
F O C=k \cdot R P M^{3}
$$

\footnotetext{
*t.cepowski@am.szczecin.pl
} 
where:

FOC - fuel oil consumption (mt),

$R P M$ - main engine revolutions ( $1 / \mathrm{min})$,

$k \quad$ - coefficient determined for specific vessel (or group of sister-vessels).

This equation (1) is commonly used in operational methods to assess and predict fuel consumption.

Contemporary systems installed on board ships provide a large amount of raw data, allowing for post-voyage analysis. This data could potentially be used to reach much better estimations of ship fuel consumption.

In this publication (Cepowski 2015), the author has presented a concept that allows the use of data recorded onboard a vessel to form mathematical relationships.

However, in the publication (Cepowski \& Drozd, 2017), the authors used this method to develop regression functions based on data recorded on a container ship over service of 96 months.

Approximating functions were calculated by the use of multidimensional data fitting techniques and a regression method. This research shows that it is possible to develop approximate fuel consumption based on on-board ship recorded data, taking into account all relevant (significant/important) ship service parameters and weather parameters. Although the equation that was developed with this method proved to be overly complicated, ie (Cepowski \& Drozd, 2017):

$$
\begin{gathered}
F O C=a 0+a 1 \cdot\left(\frac{1}{2}\right)^{\Psi}+a 2 \cdot T^{-2}+a 3 \cdot t^{1 / 7}+a 4 \cdot R P M^{5}+ \\
+a 5 \cdot L+a 6 \cdot V V+a 7 \cdot V Q^{15}+a 8 \cdot P H+a 9 \cdot P Q^{3}+a 10 \cdot \\
\cdot P P+a 11 \cdot S H+a 12 \cdot S Q^{1 / 4}+\ldots \cdot S P^{4}+a 81 \cdot S H \cdot S P \\
\cdot P P \cdot S H^{4}+a 82 \cdot P P \cdot S Q^{2}+a 83 \cdot(1 / 2)^{S H} \cdot S Q+a 84 \cdot S H \cdot S P
\end{gathered}
$$

where:

FOC - fuel consumption [t/day],

$\Phi-$ roll amplitude [deg],

$\psi$ - pitch amplitude [deg],

$M-$ number of months since last docking [-],

$T$ - mean draught [m],

$t-$ trim $[\mathrm{m}]$,

$R P M$ - engine revolutions [rev/min],

$L$ - main engine load [\%],

$V Q$ - relative wind course [deg],

$P H$-primary wave height [m],

$P Q$ - primary wave direction [deg],

$P P$ - primary wave period [s],

$\mathrm{SH}$-secondary wave height [m],

$S Q$ - secondary wave direction [deg],

$S P$ - secondary wave period [s],

a0 ... a84-coefficients

In addition, the study presented in (Cepowski \& Drozd, 2017), clearly shows a relationship between the fuel consumption of a container ship and number of months since last docking (M). These kinds of relationships are possibly related to hull and propeller fouling phenomena and have not been demonstrated before in ship theory. This phenomenon increases the resistance of the ship and increases fuel 
consumption. Mathematical modelling of this phenomenon is very important in ship theory.

\section{THE AIM OF RESEARCH}

The general purpose of the study was to determine the relationship between the fuel consumption of a container ship, hull and propeller fouling phenomena, as well as operational parameters. Data required for this research was obtained from one container vessel which has been in service for 96 months. The main ship parameters were as follows:

- length between perpendiculars $L=304 \mathrm{~m}$;

- breadth moulded B = $40 \mathrm{~m}$;

- number of TEU containers $=6500$;

- deadweight DWT $=83000 \mathrm{t}$;

- service speed $V=25$ knots.

The study presented in (Cepowski \& Drozd, 2017) and this analysis took into account a set of 11137 registered fuel consumption values and:

- loading condition parameters: mean draught and trim;

- ship propulsion system parameters, such as engine revolution and main engine load;

- ship motion parameters, such as roll and pitch amplitudes;

- sea sea-based operation parameters, such as the number of months since last docking,

- environmental condition parameters.

Parameter range values are presented in Tables 1 which fully cover typical real operational conditions both with regards to RPM (M/E loads) sets, loading (draft and trim), as well as weather conditions. The vessel was being operated within safety limits, with regards to her motions on the waves/swells.

Table 1

Minimal and maximal values

\begin{tabular}{|c|c|c|c|c|c|c|c|c|}
\hline & $\begin{array}{c}\text { FOC } \\
\text { [t/day] }\end{array}$ & $\begin{array}{c}\mathbf{F} \\
\text { [deg] }\end{array}$ & $\begin{array}{c}\mathbf{P} \\
\text { [deg] }\end{array}$ & M & $\begin{array}{c}\mathrm{T} \\
{[\mathrm{m}]}\end{array}$ & $\begin{array}{c}t \\
{[\mathrm{~m}]}\end{array}$ & $\begin{array}{c}\text { RPM } \\
\text { [rev/min] }\end{array}$ & $\begin{array}{l}\text { M/E } \\
\text { [\%] }\end{array}$ \\
\hline Min & 1.2 & 0.2 & 0.2 & 0 & 10.6 & -0.28 & 0 & 0 \\
\hline Max & 163.2 & 15 & 4.9 & 96.2 & 12.9 & 1.44 & 91 & 58 \\
\hline
\end{tabular}

Source: (Cepowski \& Drozd, 2017).

where: FOC - fuel consumption, $\mathrm{F}$ - roll amplitude, $\mathrm{P}$ - pitch amplitude, $\mathrm{M}$ - number of months since last docking, $T$ - mean draught, $t$ - trim, RPM - engine revolution, M/E - main engine load.

In the first stage, the most important ship operational parameters were selected.

A statistical analysis showed that the main engine load and engine revolutions had the most important influence on fuel consumption.

Consequently, the aim of research was to determine a relationships between the number of months since last docking (expressed as $\mathrm{M}$ ), other operational parameters and fuel consumption. These relationships can be described by the following function:

$$
F O C=f(M, L, R P M)
$$

where:

FOC - estimated interim fuel consumption;

$R P M$ - engine revolutions [rev/min],

$L$ - main engine load [\%], 
$M-$ number of months since last docking

$F-$ function for the estimation of interim fuel consumption FOC.

Function $f$ can be determined according to the formula:

$$
M, L, R P M \stackrel{f}{\rightarrow} \text { FOC }
$$

where:

$M, L, R P M$ - recorded parameter values on-board the ship,

FOC - recorded interim fuel consumption values on-board the ship.

The computational equation discovery method was used to determine the ffunction.

\section{METHODOLOGY OF RESEARCH}

Nowadays, semi-automated data analysis techniques for equation discovery are used in many areas of science.

A number of practical examples, which have already been presented in many papers (Dzeroski \& Todorovski, 2007; Koza, Mydlowec, et al, 2007; Todorovski, 2001; Zupam, Bratko, et al., 2007) are based on computational equation discovery methods. Computational equation discovery methods are based on machine learning and are described in detail in Encyclopedia of Machine Learning (Sammut \& Webb, 2011). These methods are most often based on the artificial neural network theory.

The author developed a new heuristic algorithm to semi-automatically discover the best nonlinear equation by the use of regression and evolution theory based on computational equation discovery methods. The best combinations of independent variables were randomly searched through all their possible combinations in this algorithm.

A general algorithm scheme is shown in Figure 1.

The base function collection included the set of nonlinear, exponential, power and logarithmic functions. NdCurveMaster software was developed on the basis of this algorithm by the author (Cepowski, 2017). This software was applied to discover equations presented in this paper.

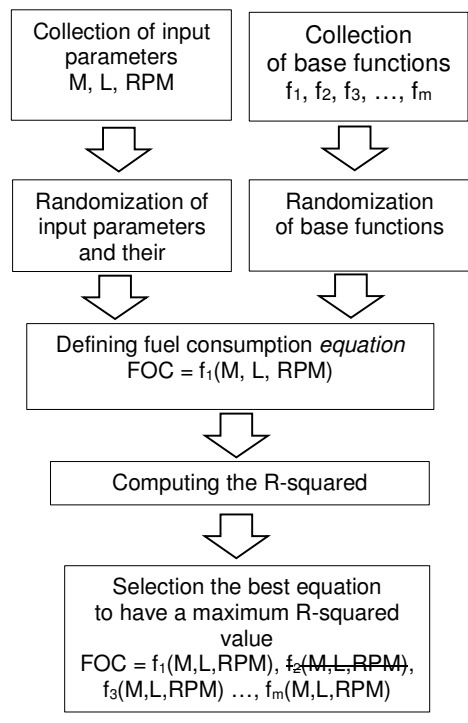

Fig. 1 The general algorithm scheme,

where: FOC is estimated fuel consumption, RPM - engine revolutions,

$L$ - main engine load, $M$ - number of months since last docking, $f$ is a formula to calculate fuel consumption FOC, $m$ is the number of formulas 


\section{RESULTS}

Using the algorithm in Fig. 1, the following equations have been developed to describe the relationship between fuel consumption, number of months since last docking, engine revolution and main engine load:

$$
\begin{gathered}
\text { FOC }=0.00166 \cdot M^{1 / 21} \cdot R P M^{2.5} \\
\text { FOC }=3.439 \cdot M^{1 / 21} \cdot L^{0.9} \\
\text { FOC }=2.801 \cdot M^{1 / 21} \cdot R P M^{1 / 21} \cdot L^{0.9}
\end{gathered}
$$

where:

FOC - estimated interim fuel consumption [t/day]

$R P M$ - engine revolutions [rev/min.],

$L-$ main engine load [\%],

$M$ - number of months since last docking [-].

The values of standard SE and the R-squared errors relating to elaborated relationships (5) - (7) are given in Table 2.

Table 2

The values of standard SE and the R-squared errors relating to the relationships mentioned above (5) - (7)

\begin{tabular}{|c|c|c|c|c|}
\hline Item & Input parameter & Equation no & Standard error SE [t/day] & R-Squared \\
\hline 1. & $\mathrm{M}, \mathrm{RPM}$ & $(5)$ & 7.07 & 0.993 \\
\hline 2. & $\mathrm{M}, \mathrm{L}$ & $(6)$ & 5.74 & 0.996 \\
\hline 3. & $\mathrm{M}, \mathrm{RPM}, \mathrm{L}$ & $(7)$ & 5.77 & 0.996 \\
\hline
\end{tabular}

Table 2 shows that the equations are characterized by their high accuracy.

Equations (5)-(7) show that the effect of hull fouling on fuel consumption can be represented by a general formula:

$$
F O C=\alpha \cdot f(R P M, L) \cdot M^{1 / 21}
$$

where:

FOC - fuel consumption,

$\alpha-$ coefficient,

$f$ - function for the estimation of the relationship between fuel consumption FOC, engine revolutions, RPM and main engine load $L$,

$M-$ number of months since last docking.

\section{CONCLUSIONS}

This research has shown that it is possible to develop relationships between fuel consumption and hull and propeller fouling phenomena using the method presented in this article.

The author's method was used to enabled the creation of accurate assessments, characterized by low standard error.

This study shows a relationship between fuel consumption and hull and propeller fouling phenomena. Equations (5), (6) and (7) take into account fuel consumption, number of months since last docking, engine revolutions and main engine load in detail. Based on these equations, formula (8) was developed. This formula has a practical application in sea vessels. These kinds of relationships have not been demonstrated before in ship theory. The results found here can be the basis for further 
research in this direction. It is hoped that this will advance the development of new ship theory.

NdCurveMaster software is highly effective, meaning significant time savings were made in the discovery for the suitable equations. A computational equation discovery method has been efficiently implemented in ndCurveMaster.

\section{REFEENCES}

Atkinson, G., Cowpe, E., Halliday, J. and Painter, D. (2017). A review of very large vapour cloud explosions: Cloud formation and explosion severity. Journal of Loss Prevention in the Process Industries, 48, pp. 367-375.

Basu, R. and Verma M. (2017). An expected consequence approach to assessing the viability of multimodal transportation of crude oil in eastern Canada. Case Studies on Transport Policy, 5(3), pp. 518-526.

Bubbico, R., Cave, S. and Mazzarotta, B. (2009). Preliminary risk analysis for LNG tankers approaching a maritime terminal. Journal of Loss Prevention in the Process Industries, 22(5), pp. 634-638.

Farfan, J. and Breyer, C. (2017). Structural changes of global power generation capacity towards sustainability and the risk of stranded investments supported by a sustainability indicator. Journal of Cleaner Production, 141, pp. 370-384.

Krata, P. and Szlapczynska, J. (2017). Ship weather routing optimization with dynamic constraints based on reliable synchronous roll prediction. Ocean Engineering, 150, pp. 124-137.

Landucci, G., Antonini, A., Tugnoli, A., Bonvicini, S., Molag, M. and Cozanni, V. (2017). HazMat transportation risk assessment: A revisitation in the perspective of the Viareggio LPG accident. Journal of Loss Prevention in the Process Industries, 49(A), pp. 36-46.

$\mathrm{Liu}, \mathrm{X}$., Li, J. andi Li, X. (2017). Study of dynamic risk management system for flammable and explosive dangerous chemicals storage area. Journal of Loss Prevention in the Process Industries, 49 (B), pp. 983-988.

Mabrouk, A., Boulmakoul, A., Karim, L. and Lbath, A. (2017). Safest and shortest itineraries for transporting hazardous materials using split points of Voronoï spatial diagrams based on spatial modeling of vulnerable zones. Procedia Computer Science, 109, pp. 156-163.

PolskieLNG.pl, (2018). Polskie LNG Official Website. [online] Available at: http://www.polskieLNG.pl

Sedlaczek, R., (2008). Boil-Off in Large and Small Scale LNG Chains, Diploma Thesis, Faculty of Engineering Science and Technology, Department of Petroleum Engineering and Applied Geophysics. Available at: http://webcache.googleusercontent.com/search?q=cache:IXeBpJEYMswJ:citeseerx.is t.psu.edu/viewdoc/download\%3Fdoi\%3D10.1.1.470.6116\%26rep\%3Drep1\%26type\% $3 \mathrm{Dpdf}+\& \mathrm{~cd}=1 \& \mathrm{hl}=\mathrm{pl} \& \mathrm{ct}=\mathrm{clnk} \& \mathrm{gl}=\mathrm{pl} \&$ client=firefox-b-ab [Accessed 22 Jan. 2018].

Ślaczka, W. (2011). Estimation of the consequences of LNG vessel tank leakage in the port of Świnoujście. Scientific Journals Maritime University of Szczecin, 25(97), pp. 70-76. 
Abstract: Nowadays, when we try to automatize all activities, there is a growing demand for energy in all forms. Increasingly we reach for new energy sources that can be problematic to store or to transport, owing to their toxicity or explosive propensity. The article examines the issues of determining danger zones occurring as a result of liquefied natural gas (LNG) release. The range of danger zones caused through LNG release depends on a multitude of factors. The basic parameter that needs to be considered is a type of the released substance as well as the manner of its release. The range of a danger zone is determined by, inter alia, the concentration of a released substance and the atmospheric conditions existing at the time when depressurization occurs. The article analyses the problem of the range of danger zones in a function of wind speed and surface roughness with a defined value of Pasquill stability for various LNG types, starting with pure methane, and ending with the so-called LNG-heavy. The difficulty of the task becomes more complicated when the analysed surface over which a depressurization incident takes place involves water. The problem deepens even further when the analysed substance possesses explosive properties. Then, apart from regular substance concentration, upper and lower flammability limit ought to be considered. Calculations were conducted with DNV-Phast software, version 7.11.

Keywords: LNG chemical composition, explosion risk area, upper and lower explosion limit 